\title{
Corrigendum: Daru et al., Decentralized, Community-Based Treatment for Drug-Resistant Tuberculosis: Bangladesh Program Experience
}

See corrected article.

Th the article, "Decentralized, community-based treatIment for drug-resistant tuberculosis: Bangladesh program experience," by Paul Daru et al. (Volume 6,
Number 3), the results section of the Abstract incorrectly cited the baseline percentages of patients who died and were lost to follow-up as $34 \%$. These baseline figures have been corrected to $14 \%$, per the data reported in the Table and main body of the article.

Cite this article as: Corrigendum: Daru et al., Decentralized, community-based treatment for drug-resistant tuberculosis: Bangladesh program experience. Glob Health Sci Pract. 2018;6(4):766. https://doi.org/10.9745/GHSP-D-18-00398 